\title{
Intradural Extramedullary Tumor Causing Compression of the Thoracic and Lumbar Vertebrae in a 22-year-old Male with Acute Myeloid Leukemia
}

\author{
Ronna Cheska V. De Leon, ${ }^{1}$ Camille Ariadne C. Tanchanco, ${ }^{2}$ Ma. Angelina L. Mirasol ${ }^{2}$ \\ and Joven Jeremius Q. Tanchuco ${ }^{3}$ \\ ${ }^{1}$ Department of Medicine, Philippine General Hospital, University of the Philippines Manila \\ ${ }^{2}$ Section of Hematology, Department of Medicine, College of Medicine and Philippine General Hospital, University of the Philippines Manila \\ ${ }^{3}$ Section of Pulmonology, Department of Medicine, College of Medicine and Philippine General Hospital, University of the Philippines Manila
}

\begin{abstract}
Myeloid sarcoma, characterized by the presence of immature myeloid cells occurring at an extramedullary site, is a rare manifestation of acute myelogenous leukemia (AML). Spinal cord compression as an initial presentation of AML is very rare with only a few reported cases. We discuss a case of a 22-year-old male who presented with bicytopenia and paraplegia. Workups were consistent with AML with monocytic differentiation. Chromosomal analysis revealed loss of $Y$ and $t$ (8;21). Spinal cord MRI showed intradural extramedullary-enhancing soft tissue lesions at levels T2 to T7 and L5 to S1, suspected to be myeloid sarcoma. Patient, however, succumbed to severe nosocomial infection prior to initiation of chemotherapy and radiotherapy.
\end{abstract}

Key Words: acute myeloid leukemia, extramedullary tumor, myeloid sarcoma, intradural tumor, $t(8 ; 21)$ translocations

\section{INTRODUCTION}

Acute myeloid leukemia (AML) is a disorder evolving from a malignantly transformed multipotential hematopoietic stem cell. It acquires successive genomic alterations, becoming a clinically overt disease. AML is a complex malignancy, with genetic, epigenetic, and phenotypic heterogeneity. ${ }^{1}$

Extramedullary AML (myeloid sarcomas) are solid tumors made of immature myeloid precursors. ${ }^{2}$ It may develop simultaneously or precede the development of AML. It may also be the initial presentation of relapse. ${ }^{3}$ Myeloid sarcomas in patients with AML are usually found in the bone, skin, soft tissue and lymph nodes. ${ }^{4}$ Central nervous system (CNS) involvement is rare, present in only around 3-9\% of AML patients. ${ }^{5}$ Among patients with CNS involvement, cases involving the spinal cord are even less common..$^{5-7}$ Spinal cord compression due to myeloid sarcoma as an initial manifestation of AML is very rare with only few reported cases. ${ }^{3}$

The predominantly neurologic presentation can Corresponding author: Joven Jeremius Q. Tanchuco, MD Section of Pulmonology Department of Medicine Philippine General Hospital University of the Philippines Manila Taft Avenue, Manila 1000, Philippines Email: jqtanchuco1@up.edu.ph mislead the diagnosis and delay the subsequent appropriate management of these patients. We present a case of a Filipino male with intradural extramedullary myeloid sarcoma causing compression of the thoracic and lumbar spinal cord as the initial presentation of AML. 


\section{CASE PRESENTATION}

A 22-year-old male with no known co-morbidities presented with a 3-month history of generalized body weakness. This was accompanied by pallor, petechial rashes, fever, abdominal pain and blood-streaked stools. Initial consult at a local hospital revealed typhoid fever and was given unrecalled antibiotics but still with persistence of blood-streaked stools. He consulted at another institution where workup revealed pancytopenia; hence acute leukemia was considered. He was then advised referral to a tertiary hospital for further workup and definitive management. However, he developed sudden onset of lower extremity weakness and numbness with associated urinary and fecal incontinence prompting consult in our institution.

At the emergency department he was weak-looking, pale, hypotensive and had generalized petechial rashes. Pertinent physical examination revealed hyperactive bowel sounds and direct epigastric tenderness. There were no palpable masses, hepatomegaly or splenomegaly. Digital rectal examination showed lax anal sphincter and black tarry stools. Lower extremity testing revealed a $0 / 5$ muscle motor strength, hyperreflexia with bilateral Babinski and sensory deficits from T12 and below.

Initial lab results revealed bicytopenia (anemia $[\mathrm{Hgb}$ $9.5 \mathrm{~g} / \mathrm{L}$ ] and thrombocytopenia [platelet count of $6.0 \mathrm{x}$ $\left.10^{3} / \mathrm{L}\right]$ ), leukocytosis (WBC $89.7 \times 10^{9} / \mathrm{L}$ ) and blasts on peripheral blood smear (Figure 1). Further workup revealed flow cytometry findings consistent with AML with evidence of monocytic differentiation (Figure 2). Karyotyping showed a $\mathrm{t}(8 ; 21)$ abnormality and a loss of $\mathrm{Y}$ chromosome (Figure 3). Spinal MRI showed isointense to hyperintense enhancing soft tissue lesions at levels T2-T7 and L5-S1 suggestive of intradural extramedullary myeloid sarcoma (Figure 4). Plain abdominal CT scan was done and showed normal sized liver and spleen with no visible masses noted within. Lymph nodes in the paraaortic, aortocaval and paracaval regions were unremarkable. There was incidental note of minimal pleural fluid collection in the dependent portions of the bilateral hemithoraces with associated passive atelectasis of the adjacent lung segments. An esophagogastroduodenoscopy and colonoscopy were done revealing erythematous gastropathy.

Definitive plan was combination intensive induction chemotherapy (cytarabine and anthracycline) and radiotherapy. However, the patient developed urinary tract infection with ESBL-negative Escherichia coli. Cultureguided antibiotic therapy with Meropenem was started but unfortunately, the patient eventually succumbed to septic shock.

\section{DISCUSSION}

AML is the most common acute leukemia in adults and accounts for approximately $80 \%$ of cases in the patient's age group., ${ }^{2,3}$ In contrast, AML accounts for less than 10 percent of acute leukemias in children less than 10 years of age. In adults, the median age at diagnosis is approximately 65 years. $^{8}$

Bone marrow aspirate smears (Figures $1 \mathrm{~A}$ and $1 \mathrm{~B}$ ) and flow cytometry findings (Figure 2) were consistent with acute myeloid leukemia with monocytic differentiation. The relatively young age of our patient ( $<60$ years) would have indicated theoretically a better prognosis had chemotherapy been started. However, his concomitant infection and presence of intradural extramedullary tumor suspected as myeloid sarcoma are indicators of poor prognosis. ${ }^{5}$

Cytogenetic studies would also help in establishing the diagnosis and prognosis for individual patients. Favorable abnormalities include: $\mathrm{t}(8 ; 21)$, inversion 16 or $\mathrm{t}(15: 17)$.

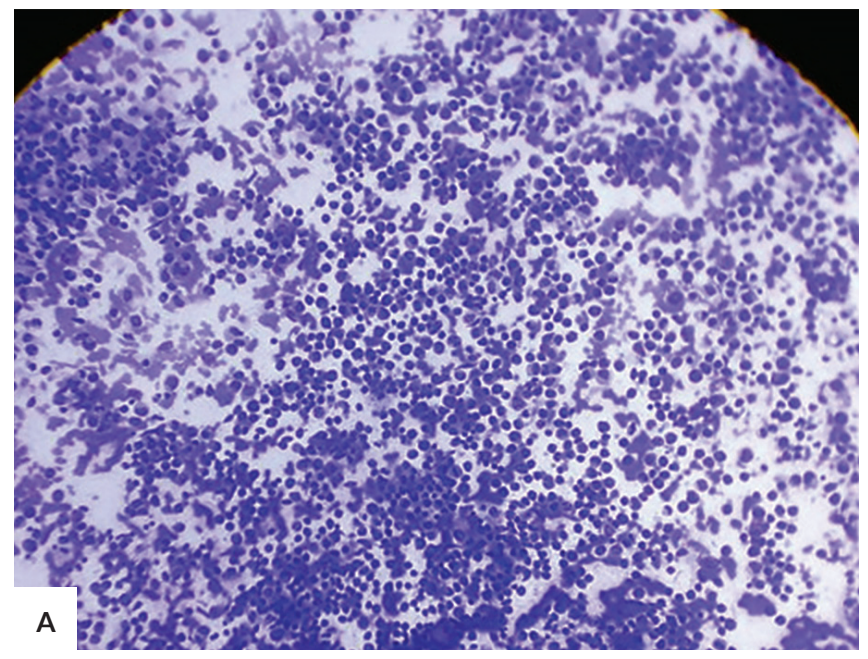

Figure 1. (A-B). BMA slides show hypercellular marrow with monotonous population of medium- to large-sized mononuclear cells with ovoid to irregular nuclei, fine to slightly coarse chromatin, few conspicuous nucleoli, and scant to moderately abundant cytoplasm. ( $\mathrm{H}$ and $\mathrm{E}$ stain. 10x magnification and 100x magnification, respectively). 

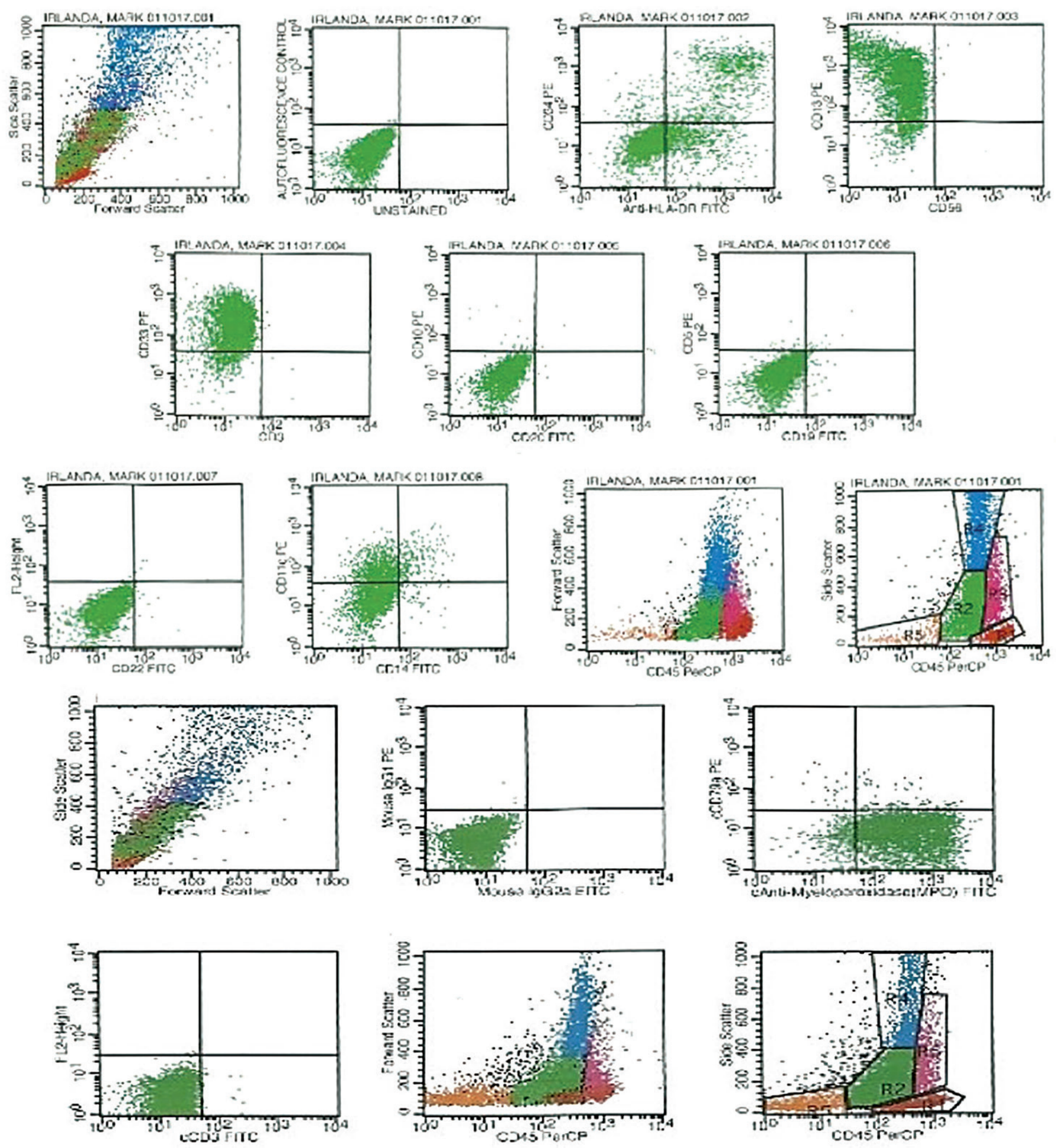

Figure 2. The flow cytometer is gated on the blast gate on $44.48 \%$ of the total population showing moderately bright CD45 expression, with low- to mid-side scatter expression. The analyzed population shows bright expression of the stem cell marker CD34, with bright expression of HLA-DR. There is expression of myeloid markers, with bright CD13 and moderately bright CD33 expression. There is moderately bright expression of the myelomonocytic markers CD11c and CD14. There is no significant expression of B-lymphoid (CD10, CD19, CD20, CD22) and T-lymphoid (CD3, CD5) and NK-cell (CD56) markers. Evaluation of cytoplasmic markers shows bright expression of the myeloid marker Myeloperoxidase (MPO), with no significant expression of the B-cell marker CCD79a and of the T-cell marker cCD3. Immuno-morphologic profile is compatible with bone marrow involvement by Acute Myeloid Leukemia (WHO Classification) with evidence of monocytic differentiation. 


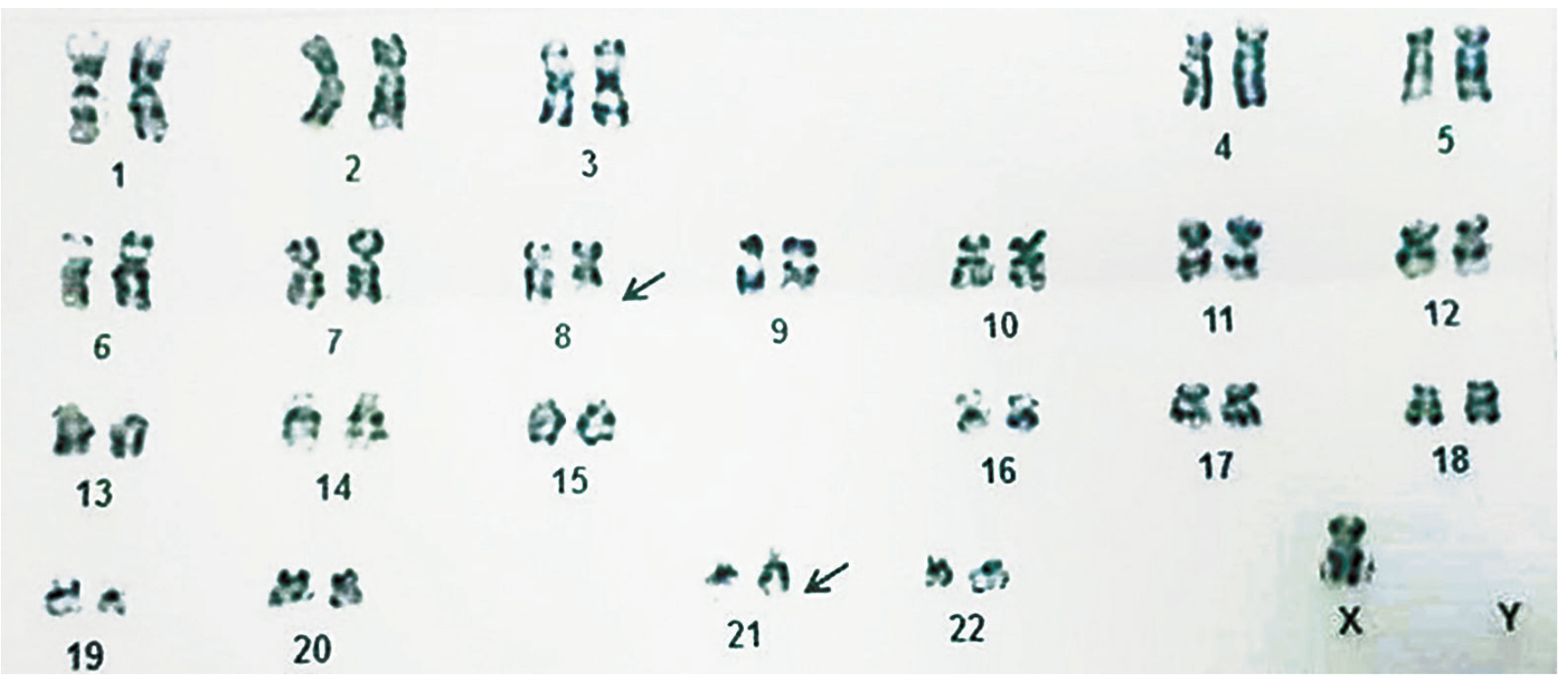

Figure 3. Chromosomal analysis revealed an abnormal male chromosome complement with a loss of chromosome $Y$ and a translocation between the long arms of chromosomes 8 and 21, seen in 6 out of 11 cells examined. The remaining 5 cells showed no clonal aberrations. Only 11 mitotic cells were available for the cytogenetic analysis from the bone marrow specimen, precluding a full 20-cell study. This limited study may not rule out mosaicism at a level that is standard for such an analysis.
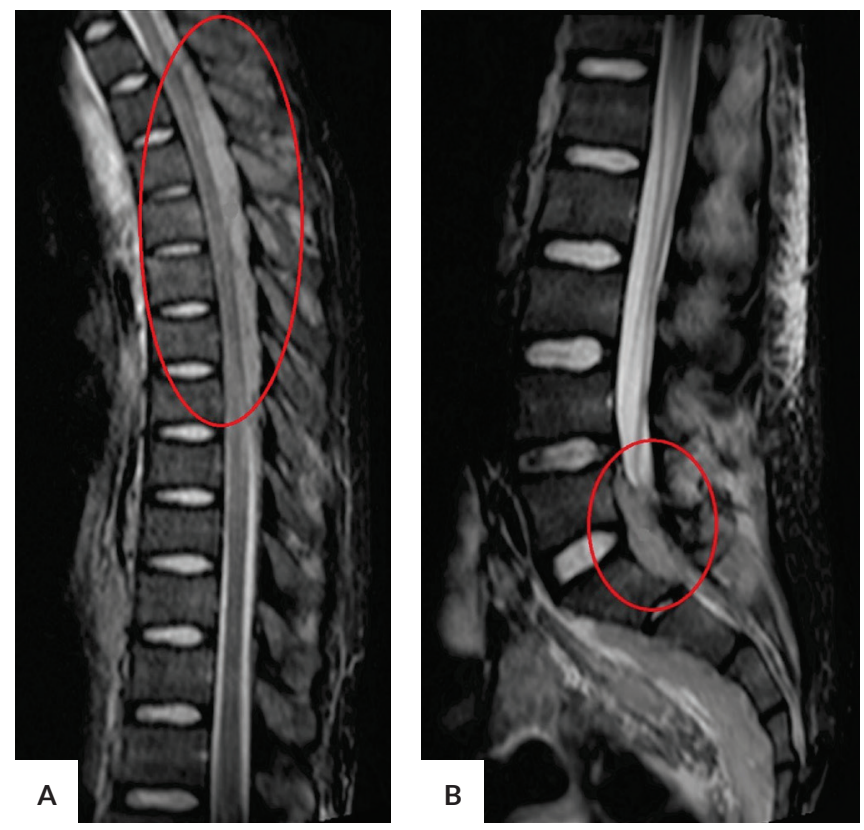

Figure 4. (A-B). Sagittal views of the thoracic and lumbar spine showing T1W1/T2W1 isointense to hyperintense intradural, extramedullary enhancing soft tissue lesions seen near the posterior aspect of T2-T7 vertebra with associated anterior displacement and mild compression of the spinal cord. A similar enhancement at the level of L5-S1 vertebra with an aggregate measurement of $12.4 \mathrm{~cm} \times 1.3 \mathrm{~cm} \times 0.6$ $\mathrm{cm}$ was also noted.
Unfavorable abnormalities include: de15 or del7, translocation or inversion of chromosome $3, \mathrm{t}(6 ; 9), \mathrm{t}(9 ; 22)$, abnormalities of chromosome 11 (at the spot q23), loss of a chromosome (monosomy) and other complex changes (those involving 3 or more chromosomes). ${ }^{5,6,9} \mathrm{~A} \mathrm{t}(8 ; 21)$ translocation (Figure 3) generally portends a good prognosis. Our patient, however, presented with the $\mathrm{t}(8 ; 21)$ translocation with an associated loss of the $\mathrm{Y}$ chromosome. Available literature shows different prognosis for these AML cases. The coexistence of these mutations points to a poorer prognosis, with uneasy remission and high risk for relapse. ${ }^{10}$

\section{Myeloid Sarcomas}

The patient presented with bilateral lower extremity weakness which was investigated. On MRI, there was presence of intradural extramedullary mass compressing the spinal cord at the levels of T2-T7 and L5-S2 (Figure 4). His neurologic deficits were consistent with compression at the level of L5 to S2. Myeloid sarcoma was highly considered based on imaging studies. Biopsies were contemplated to confirm the diagnosis however the patient did not consent. CNS involvement are more common in patients with hyperleukocytosis, and patients under two years of age. ${ }^{11,12}$ Marked elevations of the LDH and abnormalities of chromosomes 11 and 16 have also been associated with CNS disease at presentation or relapse. ${ }^{13}$ Patients with CNS involvement may be asymptomatic or complain of headache, cranial nerve palsies, or visual changes.

The most common locations of myeloid sarcomas are skin, soft tissue, bone, periosteum, and lymph nodes and 
less commonly the orbit, intestine, mediastinum, epidural region, uterus, and ovary. ${ }^{14-20}$ Central nervous system myeloid sarcomas are uncommon, usually presenting with back pain and weakness. It is proposed that this is brought about by the invasion of leukemic cells from the bone marrow into the dura mater and subarachnoid space via the Haversian canals. ${ }^{21,22}$ The most frequent spinal localization of myeloid sarcoma is in the thoracic region, followed by the lumbar and sacral area. ${ }^{3}$ Our patient had lesions both in the thoracic as well as lumbosacral areas.

CNS involvement usually portend a poorer prognosis. ${ }^{21}$ The presence of myeloid sarcomas in the CNS may present a therapeutic challenge as well since usual chemotherapy and even radiotherapy may not be able to reach these sanctuary sites. $^{22}$ Though adequately treated with chemotherapy, radiotherapy or even surgical decompression, some neurologic symptoms do not resolve probably secondary to the damage already imparted on the neurons.,22 Some patients succumb to complications such as in the case of our patient who developed catheter-related urinary tract infection. ${ }^{3}$

In past studies, myeloid sarcomas are encountered in around $15 \%$ of patients presenting with an AML associated with $\mathrm{t}(8 ; 21)$. On the other hand, $\mathrm{t}(8 ; 21)$ is only seen in $2-3 \%$ of patients presenting with myeloid sarcomas. The leukemic infiltrates seen in this genetic mutation are usually present in uncommon locations such as intraabdominal infiltration, intracerebral and intraspinal tumors, like in our patient. ${ }^{23}$

Due to the patient's demise, further workup on the mass compressing the spinal cord such as biopsies and tissue stains were not verified histologically as myeloid sarcoma. Cytologic and genetic markers can also be obtained from such masses in more ideal settings as these may help determine response and overall prognosis. ${ }^{5}$

\section{CONCLUSION}

We presented a case of a 22-year-old male initially presenting with blood-streaked stools and paraplegia. Workups revealed findings compatible with AML with monocytic differentiation and concomitant intradural extramedullary tumor of the thoracic and lumbar vertebrae (T2-T7 and L5-S2), suspected to be a myeloid sarcoma. Karyotyping studies showed $\mathrm{t}(8 ; 21)$ with a loss of $\mathrm{Y}$ chromosome. Although myeloid sarcomas can be the initial sign of AML or develop simultaneously with the disease, they are rare in the CNS, rarer still in affecting the spinal cord and causing its compression. Therapeutic strategies include chemotherapy, radiation therapy, surgical decompression and bone marrow transplantation; or a combination of these approaches. However, despite variable remission rates, those who present with a $t(8 ; 21)$ and an associated loss of $\mathrm{Y}$ chromosome point to a poorer prognosis. In addition to that, patients with neurologic sequalae more commonly succumb to hematological complications such as in our case.

\section{Statement of Authorship}

All authors participated in data collection and analysis, and approved the final version submitted.

\section{Author Disclosure}

All authors declared no conflicts of interest.

\section{Funding Source}

This paper was self-funded.

\section{REFERENCES}

1. Löwenberg B, Rowe JM. Introduction to the review series on advances in acute myeloid leukemia (AML). Blood. 2016;127(1):1. doi: 10.1182/ blood-2015-10-662684.

2. Jaffe ES, Harris NL, stein H, Vardiman JW, eds. Tumours of Haematopoietic and Lymphoid Tissues. In: Pathology and Genetics. Lyon: IARC Press; 2001. pp. 104-5.

3. Oka D, Bah A, Tokpa A, Derou L. Epidural spinal cord compression as initial clinical presentation of an acute myeloid leukaemia: case report and literature review. Chin Neurosurg J. 2016. doi: 10.1186/s41016015-0020-5

4. Pileri SA, Ascani S, Cox MC, Campidelli C, Bacci F, Piccioli M, et al. Myeloid sarcoma: clinico-pathologic, phenotypic and cytogenetic analysis of 92 adult patients. Leukemia. 2007; 21(2):340-50.

5. Schiffer CA, Gurbuxani S. Clinical manifestations, pathologic features, and diagnosis of acute myeloid leukemia [Internet]. UpToDate. 2018 [cited 2019 April 20]. Available from www.uptodate.com/contents/ clinical-manifestations-pathologic-features-and-diagnosis-ofacute-myeloid-leukemia.

6. Schiffer CA, Gurbuxani S. Classification of acute myeloid leukemia. UpToDate. 2018 [cited 2019 April 24]. Available from www. uptodate.com/contents/classification-of-acute-myeloid-leukemia.

7. Hu X, Shahab I, Lieberman IH. Spinal myeloid sarcoma "chloroma" presenting as cervical radiculopathy: case report. Global Spine J. 2015; 5(3):241-6.

8. O'Donnell MR, Tallman MS, Abboud CN, Altman JK, Appelbaum FR, Arber DA, et al. Acute myeloid leukemia, version 3.2017, NCCN clinical practice guidelines in oncology. J Natl Compr Canc Netw. 2017; 15(7):926-57.

9. Naeim F, Rao NP, Song SX, Grody WW. 21 - Acute Myeloid Leukemia, Not Otherwise Specified. In: Naeim F, Rao NP, Song SX, Grody WW, eds. Atlas of Hematopathology. Academic Press; 2013. pp. 259-81.

10. Zhu CY, Yang H, Niu JH, Zhang Q, Xie XL, Wang LJ, et al Clinical analysis of acute myeloid leukemia with $\mathrm{t}(8 ; 21)(\mathrm{q} 22 ; \mathrm{q} 22)$ and loss of Y chromosome. Zhongguo Shi Yan Xue Ye Xue Za Zhi. 2014; 22(4):950-6.

11. Cassileth PA, Sylvester LS, Bennett JM, Begg CB. High peripheral blast count in adult acute myelogenous leukemia is a primary risk factor for CNS leukemia. J Clin Oncol. 1988; 6(3):495-8.

12. Dekker AW, Elderson A, Punt K, Sixma JJ. Meningeal involvement in patients with acute nonlymphocytic leukemia. Incidence, management, and predictive factors. Cancer. 1985; 56(8):2078-82.

13. Shihadeh F, Reed V, Faderl S, Madeiros J, Mazloom A, Hadziahmetovic $\mathrm{M}$, et al. Cytogenetic profile of patients with acute myeloid leukemia and central nervous system disease. Cancer. 2012;112-7.

14. Yamauchi K, Yasuda M. Comparison in treatments of nonleukemic granulocytic sarcoma: report of two cases and a review of 72 cases in the literature. Cancer. 2002; 94(6):1739-46.

15. Paydas S, Zorludemir S, Ergin M. Granulocytic sarcoma: 32 cases and review of the literature. Leuk Lymphoma. 2006; 47(12):2527-41.

16. Neiman RS, Barcos M, Berard C, Bonner H, Mann R, Rydell $\mathrm{RE}$, et al. Granulocytic sarcoma: a clinicopathologic study of 61 biopsied cases. Cancer. 1981; 48(6):1426-37.

17. Shinagare AB, Krajewski KM, Hornick JL, Zukotynski K, Kurra V, Jagannathan JP, et al. MRI for evaluation of myeloid sarcoma 
in adults: a single-institution 10-year experience. AJR Am J Roentgenol. 2012; 199(6):1193-8.

18. Choi EK, Ha HK, Park SH, Lee SJ, Jung SE, Kim KW, et al. Granulocytic sarcoma of bowel: CT findings. Radiology. 2007; 243(3):752-9.

19. Seok JH, Park J, Kim SK, Choi JE, Kim CC. Granulocytic sarcoma of the spine: MRI and clinical review. AJR Am J Roentgenol. 2010; 194(2):485-9.

20. Byrd JC, Edenfield WJ, Shields DJ, Dawson NA. Extramedullary myeloid cell tumors in acute nonlymphocytic leukemia: a clinical review. J Clin Oncol. 1995; 13(7):1800-16.
21. Sandhu GS, Ghufoor K, Gonzalez-Garcia J, Elexpuru-Camiruaga JA. Granulocytic sarcoma presenting as cauda equina syndrome. Clin Neurol Neurosurg. 1998; 100(3):205-8.

22. Olar A, Lapadat R, Davidson CJ, Stein TD, Dahiya S, Perry A, et al. Central nervous system involvement by myeloid sarcoma: a report of 12 cases and review of the literature. Clin Neuropathol. 2016; 35(5):314-25.

23. Reikvam H, Hatfield KJ, Kittang AO, Hovland R, Bruserud $\varnothing$. Acute myeloid leukemia with the $\mathrm{t}(8 ; 21)$ translocation: clinical consequences and biological implications. J Biomed Biotechnol. 2011; 2011:104631.

\section{The Acta Medica Philippina is now accepting limited advertising for its front and back cover (colored), as well as for available spaces in some of its pages, as appropriate. For inquiries and submission of proposals, please email us at actamedicaphilippina.upm@up.edu.ph}

